\title{
Meat consumers and non-meat consumers in Germany: a characterisation based on results of the German National Nutrition Survey II
}

\author{
Franziska Koch, Thorsten Heuer*, Carolin Krems and Erika Claupein \\ Department of Nutritional Behaviour, Max Rubner-Institut, Federal Research Institute of Nutrition and Food, Karlsrube, Haid-und-Neu-Strasse 9 , \\ 76131 Karlsrube, Germany
}

(Received 25 July 2018 - Final revision received 5 May 2019 - Accepted 9 May 2019)

Journal of Nutritional Science (2019), vol. 8, e21, page 1 of 13

doi:10.1017/jns.2019.17

Abstract

Meat consumption in high-income countries is increasingly discussed due to its impact on environment and health as well as ethical considerations. The present paper aims to provide information on meat consumption behaviour, sociodemographic factors related to meat consumption and its associations with health and nutritional behaviour, based on the German National Nutrition Survey II. For 12915 participants aged $18-80$ years, food consumption was assessed by two 24-h recalls and further data by interviews. Participants were distinguished in non-meat consumers and meat consumers; meat consumers were further differentiated as low and high meat consumers ( $<86 \mathrm{~g} / \mathrm{d}$ and $\geq 86 \mathrm{~g} / \mathrm{d})$. Group differences were analysed using binary logistic and linear regression models. More non-meat consumers were found among women, young and more educated persons. They showed equal or more preferable health characteristics, had a similar energy intake but ate more plant-based foods compared with meat consumers. More high meat consumers were found among men, young and middle-aged and lower-educated persons. Compared with low meat consumers, they showed equal or less preferable health characteristics, had a higher energy intake and ate more potatoes and sauces/spices and less of most other food groups in relation to their energy intake. To conclude, sociodemographic groups differ in their meat consumption and differences in meat consumption go together with differences in health behaviour and other food consumption.

Key words: Meat consumption: Vegetarian diet: Health: Food consumption: German National Nutrition Survey II

In recent years, the high meat consumption in high-income countries has been increasingly criticised in science and society. Causes of concern are the ethical, but more recently the health and environmental implications of meat production and consumption $^{(1-3)}$

Ethical concerns about meat consumption focus on the killing of animals for human nutrition in general and the industrial production methods. Even many meat consumers experience difficulties as they do not want to hurt animals but like to eat meat at the same time (also called the 'meat paradox"(4)). However, meat consumption is rationalised by many consumers with the 4Ns: eating meat is regarded natural, normal, necessary and nice ${ }^{(5)}$. In terms of health, meat is appreciated for its nutritional value as a source of high-quality protein, $\mathrm{Fe}, \mathrm{Zn}$ and vitamin $\mathrm{B}_{12}$, but its natural content of saturated fat and cholesterol as well as some substances added in processing or formed during the cooking process are areas of concern $^{(6)}$. The high consumption levels observed in high-income countries raise public health concerns as there is epidemiological evidence for an association of meat consumption with a higher risk for common lifestyle diseases (CVD, diabetes mellitus, some types of cancer) in affluent societies ${ }^{(7)}$. Further public health risks attributable to meat production and consumption include the increase in antibiotic resistance in humans and risks from pesticide residues and foodborne pathogens ${ }^{(8)}$ as well as the adverse health effects due to climate change ${ }^{(9,10)}$.

Abbreviation: NVS II, German National Nutrition Survey II.

* Corresponding author: Thorsten Heuer, fax +49 7216625 552, email thorsten.heuer@mri.bund.de

(C) The Author(s) 2019. This is an Open Access article, distributed under the terms of the Creative Commons Attribution licence (http://creative commons.org/licenses/by/4.0/), which permits unrestricted re-use, distribution, and reproduction in any medium, provided the original work is properly cited. 
High meat production and consumption are also associated with numerous environmental issues. As mentioned before, meat consumption is a key issue in discussions about climate change. Different studies suggest that about $18-50 \%$ of global greenhouse gas emissions are attributable to livestock production $^{(11,12)}$ - although consumers tend to underestimate this problem ${ }^{(13)}$. Additional environmental problems related to meat production are land degradation and deforestation, water shortage and water pollution and loss of biodiversity ${ }^{(12)}$.

Against this background, the majority of nutrition and health organisations recommend moderate meat consumption. The recommendation of the German Nutrition Society (DGE) is to eat not more than $300-600 \mathrm{~g}$ of meat per week $^{(14)}$, which corresponds to about 43 to $86 \mathrm{~g}$ per d. Actually, men and women in Germany on average eat 142 and $76 \mathrm{~g}$ meat per d, respectively, with noticeable differences depending on age and socio-economic status ${ }^{(15)}$.

Given the social significance of meat consumption, it is important to provide further information on this topic, inter alia on consumption behaviour, the sociodemographic factors related to meat consumption and its associations with health and nutritional behaviour. The objective of this study was to use data of the German National Nutrition Survey II (NVS II) to analyse meat consumption in this regard. To explore practically relevant differences, comparisons were made (1) between persons not consuming meat and persons consuming meat in general as well as (2) between persons consuming meat in accordance with the dietary recommendations of the DGE $(<86 \mathrm{~g} / \mathrm{d})$ and persons consuming more meat than recommended $(\geq 86 \mathrm{~g} / \mathrm{d})$.

\section{Methods}

\section{Design and subjects}

The NVS II is a representative cross-sectional survey studying food consumption and further aspects of nutritional behaviour of the German population. The survey was conducted between November 2005 and January 2007 with approximately 20000 German-speaking participants 14-80 years of age and living in private households. The NVS II is based on a two-stage sampling approach of municipalities stratified by administrative district and type (first stage) and residents based on addresses from population registries stratified by sex and age (second stage). It is constructed modularly with different dietary assessment methods applied. The NVS II was approved by the German Federal Data Protection Office. Respondents were informed in detail about the study objectives, interview and examination procedures, as well as the handling of data records and analyses under pseudonymous conditions. It was made clear that participation was on a voluntary basis and could be terminated at any time. A more detailed description of the design and assessment methods of the NVS II can be obtained from the basic result report $^{(16)}$ and Heuer et al. ${ }^{(15)}$.

The present analysis is based on data from computerassisted personal/telephone interviews and two 24-h recalls conducted by telephone. This dietary assessment method was chosen for reasons of comparability with future studies, especially the German National Nutrition Monitoring (NEMONIT).

As the recommendations of the German National Nutrition Society are directed towards adults, participants aged 18-80 were selected for this analysis. Due to this restriction, data weights, which were only available for the total sample, could not be applied. However, a comparison of demographic characteristics between the NVS II study sample analysed here (n 12 915) and the Mikrozensus (providing official representative statistics of the population in Germany) reveals no substantial deviations. Women and higher-educated persons were over-represented, which is common for nutritional surveys but needs to be reflected when interpreting the data.

\section{Measures}

Food consumption and energy intake. On two nonconsecutive days, 24-h recalls were conducted by telephone using the software EPIC-SOFT ${ }^{(17)}$ (renamed GloboDiet in 2014). All reported food items were categorised into general food groups, which were described in detail by Heuer et al. ${ }^{(15)}$. Specifically for this analysis, one new food group for soya products (e.g. soya milk, tofu) was generated and the food group 'meat, meat products and sausages' was further differentiated. Meats from various animals differ substantially in their environmental and health impact as well as their sociocultural meanings. Hence, all food items out of the food group meat and meat products were classified according to their origin into beef/veal/mutton/lamb, pork, poultry, special meat or meat from unknown/mixed origin (Table 1). For the food group sausages, a clear classification of the origin was not possible. If not otherwise specified, the term 'meat' refers to total meat including meat, meat products and sausages.

According to their meat consumption, participants were classified into one of three groups: non-meat consumers were defined as persons not consuming meat but potentially fish or seafood. Participants were classified as such if they selfidentified as vegetarian (including vegan, lacto-vegetarian, ovovegetarian, ovo-lacto-vegetarian or pesco-ovo-lacto-vegetarian) and if they did not consume meat in both 24-h recall days (whereby small amounts of meat from standard recipes included in the software were not considered). All other participants were considered meat consumers and, according to their daily meat consumption, they were classified either as those not exceeding the maximum consumption recommended by the German Nutrition Society ${ }^{(14)}$ (total meat consumption $<86 \mathrm{~g} / \mathrm{d}=$ low meat consumers) or as those exceeding the recommended consumption (total meat consumption $\geq 86 \mathrm{~g} / \mathrm{d}=$ high meat consumers). Both the recommendation and the classification refer to prepared/ready-to-eat meat and include all types of meat.

Energy intake $(\mathrm{kJ} / \mathrm{d})$ was calculated as the sum of energy content from all consumed foods according to the German Nutrient Database (BLS, version 3.02) ${ }^{(18)}$. To obtain energy density $(\mathrm{kJ} / \mathrm{g})$, energy intake $(\mathrm{kJ} / \mathrm{d})$ was divided by the amount of foods (without beverages) consumed $(\mathrm{g} / \mathrm{d})$. 
Table 1. Daily consumption (g) of total meat and its subgroups among meat consumers, German National Nutrition Survey II (Arithmetic means and $95 \%$ confidence intervals)

\begin{tabular}{|c|c|c|c|c|c|c|}
\hline \multirow[b]{2}{*}{ Food group } & \multicolumn{2}{|c|}{ Men $(n$ 5713) } & \multicolumn{2}{|c|}{$\begin{array}{l}\text { Women } \\
(n 7020)\end{array}$} & \multicolumn{2}{|c|}{ Total ( $n$ 12 733) } \\
\hline & Mean & $95 \% \mathrm{Cl}$ & Mean & $95 \% \mathrm{Cl}$ & Mean & $95 \% \mathrm{Cl}$ \\
\hline Total meat (including meat, meat products and sausages) & 155 & 152,158 & 87 & 86,89 & 118 & 116,119 \\
\hline $\begin{array}{l}\text { Meat and meat products (unprocessed meats and meats processed for conservation and/or } \\
\text { refinement; including offal, minced meat and meat sauces) }\end{array}$ & 101 & 99,103 & 62 & 60,63 & 79 & 78,81 \\
\hline Beef, veal, mutton, lamb & 14 & 13,15 & 8 & 8,9 & 11 & 10,11 \\
\hline Pork & 45 & 44,47 & 26 & 25,26 & 34 & 33,35 \\
\hline Poultry (chicken, turkey, duck, goose) & 18 & 17,19 & 13 & 12,14 & 15 & 15,16 \\
\hline Special meat (e.g. game, rabbit, horse, quail) & 2 & 1,2 & 1 & 1,1 & 1 & 1,1 \\
\hline Unknown or mixed meat & 22 & 21,23 & 14 & 13,15 & 18 & 17,18 \\
\hline Sausages (mixture of chopped meat, fat tissue and flavouring ingredients; of all origins) & 54 & 52,55 & 26 & 25,27 & 38 & 38,39 \\
\hline
\end{tabular}

\section{Sociodemographic and health data}

Information on sociodemographic and health data was collected in a computer-assisted personal or telephone interview. Information on sex, age, country of birth and household size as well as smoking status and subjective health were directly obtained from the interview. For social status, three indicators were constructed and analysed separately: The education score was based on the educational, vocational and academic qualifications of the respondent. The score for the occupational status of the principal earner of the household was based on the type of employment and the qualification level of that person. Per capita income was calculated as monthly household net income (mid-point of class interval) divided by the number of persons in the household. For all three indicators, participants were divided into three groups of about equal size (low, middle, high). To obtain information about regional structure, municipalities were categorised according to their 'use density' (number of inhabitants and employees in the area) into large cities, medium cities and suburbs and small cities and rural areas ${ }^{(19)}$. BMI was calculated as body weight $(\mathrm{kg})$ divided by body height $(\mathrm{m})$ squared and categorised into underweight, normal weight, preobese and obese according to the cut-off points provided by the $\mathrm{WHO}^{(20)}$. Body height and weight were either measured in the personal interview or obtained from self-reports in the telephone interview. Missing values for BMI ( $n$ 32) were replaced by mean values calculated for sex and age. Information on sports activities (yes/no) was collected in an additional questionnaire, which was not completed by all participants in the study sample. Therefore, the analyses on sports activities are based on a smaller sample ( $n$ 8831).

\section{Statistical analysis}

All statistics were performed using SAS 9.3 (SAS Institute, Inc.). As sex has been shown to be a major factor affecting meat consumption, all analyses were done separately for men and women. Categorical and metric variables are presented as percentages and arithmetic means with $95 \% \mathrm{CI}$, respectively. Although values for meat consumption were not normally distributed, arithmetic means rather than median values were chosen. This presentation was used because most meat subgroups show median intakes of zero, which are of restricted use for comparisons and therefore not considered appropriate.

Prevalences of non-meat consumption, and low and high meat consumption in sociodemographic groups were compared using $95 \%$ CI with non-overlapping intervals indicating significant differences. Independent associations between sociodemographic characteristics and meat consumption level were examined in binary logistic regression models with non-meat consumption (reference: meat consumption) and high meat consumption (reference: low meat consumption) as dependent variables. Results are presented as OR with $95 \% \mathrm{CI}$, where intervals not including the value ' 1 ' indicate significant differences.

Differences in health and nutritional behaviour between non-meat consumers and meat consumers as well as between high meat and low meat consumers (independent variables) were examined either using binary logistic regression models (dependent variables: health-related characteristics) or linear regression models (dependent variables: energy and food intake) as appropriate. Results are presented as unadjusted and adjusted OR (with $95 \% \mathrm{CI}$ ) and regression coefficients (with $95 \% \mathrm{CI}$, where intervals not including the value ' 0 ' indicate significant differences), respectively. Adjustment was made for sociodemographic factors and/or energy intake.

To examine if categorisation into groups according to DGE reference values affected results, analyses were also performed with the amount of meat consumed as continuous variable. Altogether, the results were largely comparable but the consideration of reference values allows assessing the practical relevance of the results and improves clarity of interpretation.

\section{Results}

In total, 5757 men and 7158 women aged 18-80 years completed the interview and two 24-h recalls. Participants had a mean age of 48 years and about $30 \%$ had completed 12 or 13 years of school education. A description of the study sample regarding the variables used in the analysis is presented in Table 2. 
Table 2. Characteristics of the German National Nutrition Survey II (Numbers of participants and percentages)

\begin{tabular}{|c|c|c|c|c|}
\hline \multirow[b]{2}{*}{ Characteristic } & \multicolumn{2}{|c|}{ Men (44.6 \%) } & \multicolumn{2}{|c|}{$\begin{array}{l}\text { Women } \\
(55.4 \%)\end{array}$} \\
\hline & $n$ & $\%$ & $n$ & $\%$ \\
\hline Age group (years) & 5757 & & 7158 & \\
\hline $18-34$ & & $20 \cdot 6$ & & $20 \cdot 1$ \\
\hline $35-64$ & & $59 \cdot 2$ & & $61 \cdot 3$ \\
\hline $65-80$ & & $20 \cdot 2$ & & $18 \cdot 6$ \\
\hline Education (score) & 5757 & & 7158 & \\
\hline Low & & 27.9 & & $32 \cdot 7$ \\
\hline Middle & & $29 \cdot 2$ & & 33.2 \\
\hline High & & $43 \cdot 0$ & & 34.0 \\
\hline $\begin{array}{l}\text { Occupational status of the principal } \\
\text { earner (score) }\end{array}$ & 5757 & & 7158 & \\
\hline Low & & 35.4 & & 34.9 \\
\hline Middle & & $46 \cdot 7$ & & $50 \cdot 3$ \\
\hline High & & 17.9 & & $14 \cdot 8$ \\
\hline Per capita income & 5130 & & 6069 & \\
\hline Low & & 29.7 & & $35 \cdot 1$ \\
\hline Middle & & $31 \cdot 3$ & & 29.6 \\
\hline High & & $39 \cdot 0$ & & $35 \cdot 3$ \\
\hline Country of birth & 5744 & & 7142 & \\
\hline Germany & & $91 \cdot 6$ & & 91.0 \\
\hline Another country & & 8.4 & & $9 \cdot 0$ \\
\hline Regional structure & 5757 & & 7158 & \\
\hline Small cities and rural areas & & 28.9 & & $26 \cdot 9$ \\
\hline Medium cities and suburbs & & $35 \cdot 2$ & & $35 \cdot 3$ \\
\hline Large cities & & 35.9 & & 37.8 \\
\hline Household size & 5753 & & 7152 & \\
\hline 1 person & & $14 \cdot 0$ & & $15 \cdot 1$ \\
\hline 2 persons & & $40 \cdot 7$ & & $40 \cdot 3$ \\
\hline 3 and more persons & & $45 \cdot 3$ & & 44.6 \\
\hline BMI & 5757 & & 7158 & \\
\hline Underweight & & 0.6 & & 1.6 \\
\hline Normal weight & & $34 \cdot 2$ & & $50 \cdot 8$ \\
\hline Preobese & & $47 \cdot 1$ & & 29.2 \\
\hline Obese & & $18 \cdot 1$ & & $18 \cdot 4$ \\
\hline Smoking status & 5748 & & 7145 & \\
\hline Smoker & & 23.5 & & $18 \cdot 2$ \\
\hline Occasional smoker & & $6 \cdot 0$ & & $5 \cdot 2$ \\
\hline Former smoker & & $29 \cdot 1$ & & $18 \cdot 6$ \\
\hline Non-smoker & & 41.4 & & 58.0 \\
\hline Subjective health status & 5751 & & 7150 & \\
\hline Very good & & $17 \cdot 1$ & & $16 \cdot 0$ \\
\hline Good & & $58 \cdot 3$ & & 60.7 \\
\hline Moderate & & 20.9 & & $20 \cdot 0$ \\
\hline Poor & & $3 \cdot 2$ & & $2 \cdot 8$ \\
\hline Very poor & & 0.5 & & 0.5 \\
\hline Sports activities* & 3863 & & 4968 & \\
\hline Yes & & $57 \cdot 3$ & & 59.9 \\
\hline No & & $42 \cdot 7$ & & $40 \cdot 1$ \\
\hline
\end{tabular}

* Information obtained from an additional questionnaire in a subsample.

\section{Meat consumption level}

Based on the self-reports checked for consistency, forty-four male $(0.8 \%)$ and 138 female $(1.9 \%)$ non-meat consumers between 18 and 80 years of age were identified.

Among meat consumers, the mean daily meat consumption was $118 \mathrm{~g}$ (Table 1) (total sample with non-meat consumers: $116 \mathrm{~g}$; median daily meat consumption: $99 \mathrm{~g}$ ). On average, women's meat consumption was at the edge of the maximum recommended amount of $86 \mathrm{~g} / \mathrm{d}$. In contrast, men's average meat consumption exceeded this value by $80 \%$. A higher consumption among men compared with women was observed for all types of meat. When comparing energy-adjusted values, differences between men and women were smaller but still significant, except for meats of special origin (data not shown).

However, the different types of meat constituted a comparable proportion of all meats among men and women: For both sexes, the consumption of meat and meat products accounted for about two-thirds of the total meat consumption while one-third was comprised of sausages. Pork and pork products were by far the most consumed. Meat of unknown or mixed origins - of which about half was minced meat - and poultry were consumed in comparable amounts, while beef, veal, mutton or lamb was consumed in slightly lower amounts.

Considering their individual daily meat consumption, a little less than half (44\%) of women and almost three-quarters $(73 \%)$ of men were classified as high meat consumers exceeding the maximum recommended daily intake of $86 \mathrm{~g}$ meat per $\mathrm{d}$.

\section{Sociodemographic characteristics and meat consumption level}

Besides the pronounced sex-specific differences in the prevalence of non-meat consumption, low and high meat consumption, some further noteworthy sociodemographic differences were observed. Fig. 1 shows the prevalence of non-meat consumption and high meat consumption in selected age groups, while Table 3 shows the prevalence rates for further sociodemographic groups.

The prevalence of non-meat consumption was highest among younger adults (18-34 years), in a middle range among middle-aged adults (35-64 years) and lowest among the elderly (65-80 years) for both men and women (Fig. 1(a)). The proportion of non-meat consumers was also higher among more educated persons, among persons with high compared with middle (but not low) per capita income, among persons living in large cities (compared with persons in both other regions combined), and among persons living in single households. Multiple logistic regression models with sociodemographic characteristics as independent variables and non-meat consumption as the dependent variable (Table 4) confirm sex, age, education and household size as independent predictors of non-meat consumption. Separate results for men and women are presented for the sake of completeness, but especially for men the sample size is too small to detect meaningful differences.

The detailed examination of the prevalence of high meat consumption among age groups (Fig. 1(b)) revealed no clear pattern. Among men, high meat consumption was more prevalent among young and middle-aged adults compared with elderly. Among women, the proportion of high meat consumers was highest among middle-aged adults and comparable among young adults and elderly. High meat consumption was also more prevalent among persons with lower socio-economic status (specifically among those with low and middle education, low occupational status of the principal earner and low per capita income), among those living in small cities and rural areas (compared with large cities) and among those living in multi-person households (compared with 



Fig. 1. Prevalences (with $95 \%$ confidence intervals) of non-meat consumption (a) and high meat consumption (b) among selected age groups, German National Nutrition Survey II.

single- and two-person households) for both sexes (Table 3). In Table 5 , the results of separate multiple logistic regression models for men, women and the total sample are displayed with sociodemographic factors as independent variables and high meat consumption as the dependent variable. Male sex could be confirmed as a major predictor of high meat consumption. The model including sex explains about $14 \%$ of the variance in meat consumption level while the sexspecific models can only explain about $3 \%$ of the variance. Lower education and a rather rural setting could be confirmed as independent predictors of high meat consumption among men and women. Age, however, was only significant among

Table 3. Prevalences of non-meat consumption, and low and high meat consumption among sociodemographic groups, German National Nutrition Survey II (Percentages and $95 \%$ confidence intervals)

\begin{tabular}{|c|c|c|c|c|c|c|c|c|c|c|c|c|}
\hline & \multicolumn{6}{|c|}{ Men } & \multicolumn{6}{|c|}{ Women } \\
\hline & & & \multicolumn{4}{|c|}{ Meat consumers ( $n$ 5713) } & & & \multicolumn{4}{|c|}{ Meat consumers ( $n$ 7020) } \\
\hline & \multicolumn{2}{|c|}{$\begin{array}{c}\text { Non-meat } \\
\text { consumers } \\
(n 44)\end{array}$} & \multicolumn{2}{|c|}{$\begin{array}{l}\text { Low meat } \\
\text { consumers } \\
(n 1509)\end{array}$} & \multicolumn{2}{|c|}{$\begin{array}{l}\text { High meat } \\
\text { consumers } \\
(n \text { 4204) }\end{array}$} & \multicolumn{2}{|c|}{$\begin{array}{c}\text { Non-meat } \\
\text { consumers } \\
(n 138)\end{array}$} & \multicolumn{2}{|c|}{$\begin{array}{l}\text { Low meat } \\
\text { consumers } \\
(n \text { 3899) }\end{array}$} & \multicolumn{2}{|c|}{$\begin{array}{c}\text { High meat } \\
\text { consumers } \\
(n 3121)\end{array}$} \\
\hline & $\%$ & $95 \% \mathrm{Cl}$ & $\%$ & $95 \% \mathrm{Cl}$ & $\%$ & $95 \% \mathrm{Cl}$ & $\%$ & $95 \% \mathrm{Cl}$ & $\%$ & $95 \% \mathrm{Cl}$ & $\%$ & $95 \% \mathrm{Cl}$ \\
\hline All participants & 0.8 & $0.6,1.0$ & $26 \cdot 2$ & $25 \cdot 1,27 \cdot 4$ & 73.0 & $71 \cdot 9,74 \cdot 2$ & 1.9 & $1 \cdot 6,2 \cdot 3$ & 54.5 & $53 \cdot 3,55 \cdot 6$ & $43 \cdot 6$ & $42 \cdot 5,44 \cdot 8$ \\
\hline \multicolumn{13}{|l|}{ Education } \\
\hline Low & 0.1 & $0.0,0.4$ & $22 \cdot 7$ & $20 \cdot 1,24 \cdot 8$ & $77 \cdot 2$ & $75 \cdot 0,79 \cdot 2$ & 0.9 & $0.6,1.4$ & $52 \cdot 8$ & $50.7,54.8$ & $46 \cdot 3$ & $44 \cdot 3,48 \cdot 4$ \\
\hline Middle & 0.7 & $0.4,1.3$ & 22.9 & $20 \cdot 9,25 \cdot 0$ & $76 \cdot 4$ & $74.2,78.4$ & 1.6 & $1 \cdot 1,2 \cdot 2$ & 52.4 & $50.4,54.4$ & $46 \cdot 0$ & $44 \cdot 0,48 \cdot 0$ \\
\hline High & 1.2 & $0.8,1.7$ & 30.7 & $28 \cdot 9,32 \cdot 6$ & $68 \cdot 1$ & $66 \cdot 2,69 \cdot 9$ & 3.2 & $2 \cdot 6,4.0$ & 58.1 & $56 \cdot 1,60 \cdot 1$ & 38.7 & $36 \cdot 7,40 \cdot 6$ \\
\hline \multicolumn{13}{|c|}{ Occupational status of principal earner } \\
\hline Low & 0.7 & $0.4,1.2$ & $22 \cdot 6$ & $20 \cdot 8,24.5$ & $76 \cdot 6$ & $74.7,78.4$ & 1.3 & $0.9,1.9$ & 51.8 & $49 \cdot 8,53 \cdot 8$ & $46 \cdot 9$ & $44.9,48 \cdot 9$ \\
\hline Middle & 0.8 & $0.5,1.2$ & $28 \cdot 2$ & $26 \cdot 5,30 \cdot 0$ & $70 \cdot 9$ & $69 \cdot 2,72 \cdot 7$ & $2 \cdot 3$ & $1 \cdot 8,2 \cdot 8$ & 55.9 & $54 \cdot 3,57 \cdot 6$ & $41 \cdot 8$ & $40 \cdot 2,43 \cdot 1$ \\
\hline High & 0.7 & $0.3,1.4$ & 28.0 & $25 \cdot 3,30 \cdot 8$ & $71 \cdot 3$ & $68.5,74 \cdot 1$ & $2 \cdot 2$ & $1 \cdot 4,3 \cdot 2$ & $55 \cdot 8$ & $52 \cdot 8,58 \cdot 8$ & $42 \cdot 0$ & $39 \cdot 0,45 \cdot 1$ \\
\hline \multicolumn{13}{|l|}{ Per capita income } \\
\hline Low & 0.7 & $0.4,1.3$ & 23.4 & $21 \cdot 3,25 \cdot 6$ & $75 \cdot 9$ & $73.7,78.0$ & 1.5 & $1 \cdot 0,2 \cdot 1$ & 51.5 & $49.4,53.6$ & $47 \cdot 0$ & $44 \cdot 9,49 \cdot 2$ \\
\hline Middle & 0.2 & $0.1,0.6$ & $25 \cdot 8$ & $23 \cdot 7,28 \cdot 0$ & 73.9 & $71 \cdot 7,76 \cdot 1$ & $1 \cdot 2$ & $0.7,1 \cdot 8$ & $54 \cdot 8$ & $52 \cdot 4,57 \cdot 1$ & $44 \cdot 1$ & $41 \cdot 7,46 \cdot 4$ \\
\hline High & 1.1 & $0.6,1 \cdot 6$ & 28.7 & $26 \cdot 7,30 \cdot 7$ & $70 \cdot 3$ & $68 \cdot 2,72 \cdot 3$ & $2 \cdot 5$ & $1 \cdot 9,3 \cdot 2$ & 57.6 & $55.4,59.7$ & $40 \cdot 0$ & $37 \cdot 9,42 \cdot 1$ \\
\hline \multicolumn{13}{|l|}{ Country of birth } \\
\hline Germany & 0.8 & $0.5,1.0$ & $26 \cdot 2$ & $25 \cdot 0,27 \cdot 4$ & 73.0 & $71 \cdot 8,74 \cdot 2$ & $2 \cdot 0$ & $1 \cdot 7,2 \cdot 4$ & $54 \cdot 6$ & $53 \cdot 4,55 \cdot 8$ & $43 \cdot 4$ & $42 \cdot 2,44 \cdot 6$ \\
\hline Another country & 0.8 & $0 \cdot 2,2 \cdot 1$ & $25 \cdot 9$ & $22 \cdot 0,30 \cdot 0$ & $73 \cdot 3$ & $69 \cdot 1,77 \cdot 2$ & $1 \cdot 1$ & $0.4,2 \cdot 2$ & $53 \cdot 2$ & $49 \cdot 2,57 \cdot 1$ & $45 \cdot 7$ & $41 \cdot 8,49 \cdot 7$ \\
\hline \multicolumn{13}{|l|}{ Regional structure } \\
\hline Small cities and rural areas & 0.7 & $0.4,1.3$ & $22 \cdot 5$ & $20 \cdot 5,24 \cdot 6$ & $76 \cdot 8$ & $74 \cdot 6,78 \cdot 8$ & 1.5 & $1 \cdot 0,2 \cdot 1$ & $52 \cdot 3$ & $50 \cdot 0,54 \cdot 5$ & $46 \cdot 3$ & $44 \cdot 0,48 \cdot 5$ \\
\hline Medium cities and suburbs & 0.5 & $0.2,0.9$ & $26 \cdot 6$ & $24 \cdot 7,28 \cdot 6$ & $72 \cdot 9$ & $70 \cdot 9,74.9$ & 1.7 & $1 \cdot 2,2 \cdot 3$ & $51 \cdot 7$ & $49.7,53.6$ & $46 \cdot 6$ & $44 \cdot 7,48.6$ \\
\hline Large cities & $1 \cdot 1$ & $0.7,1.6$ & $28 \cdot 8$ & $26 \cdot 9,30 \cdot 8$ & $70 \cdot 1$ & $68 \cdot 1,72 \cdot 1$ & 2.5 & $1 \cdot 9,3 \cdot 1$ & $58 \cdot 7$ & $56 \cdot 8,60 \cdot 5$ & 38.9 & $37 \cdot 0,40 \cdot 7$ \\
\hline \multicolumn{13}{|l|}{ Household size } \\
\hline 1 person & $2 \cdot 2$ & $1 \cdot 3,3.5$ & $28 \cdot 1$ & $25 \cdot 0,31 \cdot 4$ & $69 \cdot 7$ & $66 \cdot 3,72 \cdot 8$ & 3.0 & $2 \cdot 0,4 \cdot 2$ & 60.5 & $57.5,63.4$ & $36 \cdot 6$ & $33 \cdot 7,39 \cdot 5$ \\
\hline 2 persons & 0.4 & $0.2,0.8$ & 28.9 & $27 \cdot 0,30 \cdot 7$ & $70 \cdot 7$ & $68.8,72 \cdot 6$ & 1.6 & $1 \cdot 2,2 \cdot 2$ & $56 \cdot 4$ & $54 \cdot 5,58 \cdot 2$ & $42 \cdot 0$ & $40 \cdot 2,43 \cdot 8$ \\
\hline 3 and more persons & 0.6 & $0.3,1 \cdot 0$ & $23 \cdot 3$ & $21 \cdot 7,25 \cdot 0$ & $76 \cdot 1$ & $74.4,77.7$ & 1.9 & $1.4,2.4$ & $50 \cdot 8$ & $49 \cdot 0,52 \cdot 5$ & 47.4 & $45 \cdot 6,49 \cdot 1$ \\
\hline
\end{tabular}


Table 4. Sociodemographic predictors of non-meat consumption, German National Nutrition Survey II (Odds ratios and $95 \%$ confidence intervals)

\begin{tabular}{|c|c|c|c|c|c|c|}
\hline & \multicolumn{6}{|c|}{ Non-meat consumption (Ref. meat consumption) } \\
\hline & \multicolumn{2}{|c|}{ Men $(n 5130)\left(R^{2} 0.12\right)$} & \multicolumn{2}{|c|}{ Women $\left(n\right.$ 6069) $\left(R^{2} 0.06\right)$} & \multicolumn{2}{|c|}{ Total $\left(n 11\right.$ 199) $\left(R^{2} 0.09\right)$} \\
\hline & OR & $95 \% \mathrm{Cl}$ & OR & $95 \% \mathrm{Cl}$ & OR & $95 \% \mathrm{Cl}$ \\
\hline \multicolumn{7}{|l|}{ Sex } \\
\hline Men & - & - & - & - & Ref. & \\
\hline Women & - & - & - & - & $2 \cdot 65^{*}$ & $1.81,3.89$ \\
\hline \multicolumn{7}{|l|}{ Age group (years) } \\
\hline $18-34$ & $5 \cdot 29^{\star}$ & $1 \cdot 13,24 \cdot 74$ & $2 \cdot 51^{*}$ & $1 \cdot 23,5 \cdot 13$ & $3 \cdot 11^{*}$ & $1.66,5.85$ \\
\hline $35-64$ & 2.66 & $0.59,11.89$ & 1.33 & $0.68,2.60$ & $1 \cdot 61$ & $0.89,2.94$ \\
\hline $65-80$ & Ref. & & & & & \\
\hline \multicolumn{7}{|l|}{ Education } \\
\hline Low & Ref. & & & & & \\
\hline Middle & $9.51^{*}$ & $1 \cdot 22,74 \cdot 21$ & 1.73 & $0.89,3.37$ & $2 \cdot 23^{*}$ & $1 \cdot 21,4 \cdot 10$ \\
\hline High & $12 \cdot 58^{*}$ & $1.67,94.45$ & $3 \cdot 26^{*}$ & $1.74,6.09$ & $3.81^{*}$ & $2 \cdot 14,6 \cdot 79$ \\
\hline \multicolumn{7}{|l|}{ Per capita income } \\
\hline Low & Ref. & & & & & \\
\hline Middle & 0.50 & $0.15,1.66$ & 0.83 & $0.47,1.47$ & 0.74 & $0.44,1.25$ \\
\hline High & 0.92 & $0.41,2.07$ & 1.23 & $0.74,2.04$ & 1.12 & $0.73,1.72$ \\
\hline \multicolumn{7}{|l|}{ Regional structure } \\
\hline Small cities and rural areas & Ref. & & & & & \\
\hline Medium cities and suburbs & 0.60 & $0.23,1.53$ & 1.04 & $0.59,1.86$ & 0.90 & $0.56,1.47$ \\
\hline Large cities & 0.99 & $0.45,2.19$ & 1.57 & $0.93,2.66$ & 1.39 & $0.90,2 \cdot 15$ \\
\hline \multicolumn{7}{|l|}{ Household size } \\
\hline 1 person & $4.06^{\star}$ & $1.67,9.89$ & $1.86^{*}$ & $1.04,3.33$ & $2 \cdot 46^{*}$ & $1.52,3.98$ \\
\hline 2 persons & 1.33 & $0.51,3.48$ & 1.24 & $0.77,2 \cdot 01$ & 1.28 & $0.83,1.97$ \\
\hline 3 and more persons & Ref. & & & & & \\
\hline
\end{tabular}

Ref., reference.

* Significant difference indicated when $95 \% \mathrm{Cl}$ does not include the value ' 1 '.

† OR from multiple logistic regressions with non-meat consumption (Ref. meat consumption) as the dependent variable and sociodemographic factors as independent variables.

males while household size was only significant among females in the adjusted models.

\section{Meat consumption level and health-related characteristics}

Female non-meat consumers were more likely to have a normal weight, do sports and consider their health status as very good compared with female meat consumers (Table 6). For males, similar differences in weight and subjective health were observed in bivariate analyses but did not reach significance in the adjusted logistic regression models.

Among female meat consumers, those with high meat consumption were less likely to have a normal weight, do sports and be a non-smoker. Among male meat consumers, a significant difference in the adjusted models was only observed for smoking status; male high meat consumers were less likely to be non-smokers than low meat consumers.

\section{Meat consumption level and energy intake and food consumption}

There was no significant difference in energy intake between non-meat consumers and meat consumers, although non-meat consumers tended to consume foods of lower energy density (Table 7). They ate more cereals and cereal products, total vegetables (vegetables, vegetable products, mushrooms and pulses) and soya products compared with meat consumers (Tables 8 and 9). Female non-meat consumers additionally ate more fruit and fruit products, nuts and seeds and sauces and spicy ingredients but less of potatoes and potato products, eggs and fats and oils compared with female meat consumers. Since there were no differences in energy intakes between nonmeat consumers and meat consumers, energy adjustment alone had no effect on these results. When additionally adjusting for sociodemographic differences, male non-meat consumers ate more bread, potatoes and potato products, total vegetables and soya products and female non-meat consumers ate more cereals and cereal products, total vegetables, fruit and fruit products, nuts and seeds and soya products compared with meat consumers. To summarise, non-meat consumers ate more foods of plant origin and a similar amount of other foods of animal origin compared with meat consumers.

Among meat consumers, substantial differences in energy intakes were observed: male and female high meat consumers' energy intake was 1883 and $1212 \mathrm{~kJ}$ higher than that of low meat consumers, respectively (Table 7). Solely from meat, male and female high meat consumers had a higher energy intake of 1398 and $911 \mathrm{~kJ}$ compared with low meat consumers, respectively. High meat consumers also consumed foods of higher energy density.

High meat consumers of both sexes ate more bread, potatoes and potato products, fats and oils, sauces and spicy ingredients and confectionery but less fruit and fruit products, milk, dairy products and cheese, fish, fish products and seafood, soups and soya products than low meat consumers (Tables 8 and 9). Since both groups of meat consumers differed in their energy intake, energy adjustment seriously 
Table 5. Sociodemographic predictors of high meat consumption, German National Nutrition Survey II $†$ (Odds ratios and $95 \%$ confidence intervals)

\begin{tabular}{|c|c|c|c|c|c|c|}
\hline & \multicolumn{6}{|c|}{ High meat consumption (Ref. low meat consumption) } \\
\hline & \multicolumn{2}{|c|}{ Men $(n 5094)\left(R^{2} 0.03\right)$} & \multicolumn{2}{|c|}{ Women $\left(n\right.$ 5964) $\left(R^{2} 0.03\right)$} & \multicolumn{2}{|c|}{ Total $(n 11058)\left(R^{2} 0.14\right)$} \\
\hline & OR & $95 \% \mathrm{Cl}$ & OR & $95 \% \mathrm{Cl}$ & OR & $95 \% \mathrm{Cl}$ \\
\hline \multicolumn{7}{|l|}{ Sex } \\
\hline Men & - & - & - & - & $3.68^{\star}$ & $3.39,4.00$ \\
\hline Women & - & - & - & - & Ref. & \\
\hline \multicolumn{7}{|l|}{ Age group (years) } \\
\hline 18-34 & $1.39^{*}$ & $1 \cdot 11,1.72$ & 1.04 & $0.86,1.26$ & $1 \cdot 20^{*}$ & $1.04,1.39$ \\
\hline $35-64$ & $1.53^{*}$ & $1.29,1.82$ & $1 \cdot 16$ & $0.99,1.35$ & $1.33^{*}$ & $1.19,1.48$ \\
\hline $65-80$ & Ref. & & & & & \\
\hline \multicolumn{7}{|l|}{ Education } \\
\hline Low & $1.50^{\star}$ & $1 \cdot 26,1 \cdot 80$ & $1 \cdot 32^{*}$ & $1.14,1.52$ & $1.40^{*}$ & $1.26,1.57$ \\
\hline Middle & $1.38^{\star}$ & $1.18,1.62$ & $1.30^{*}$ & $1.14,1.48$ & $1.34^{*}$ & $1.21,1.48$ \\
\hline High & Ref. & & & & & \\
\hline \multicolumn{7}{|l|}{ Occupational position } \\
\hline Low & 1.14 & $0.92,1.40$ & 1.13 & $0.95,1.35$ & 1.14 & $1.00,1.30$ \\
\hline Middle & 0.97 & $0.85,1.21$ & 0.97 & $0.82,1.13$ & 0.97 & $0.86,1.09$ \\
\hline High & Ref. & & & & & \\
\hline \multicolumn{7}{|l|}{ Per capita income } \\
\hline Low & 1.02 & $0.85,1.21$ & 1.00 & $0.86,1.15$ & 1.01 & $0.90,1.13$ \\
\hline Middle & 1.06 & $0.90,1.25$ & 0.95 & $0.82,1 \cdot 10$ & 1.00 & $0.89,1.11$ \\
\hline High & Ref. & & & & & \\
\hline \multicolumn{7}{|l|}{ Regional structure } \\
\hline Small cities and rural areas & $1 \cdot 31^{*}$ & $1.11,1.54$ & $1 \cdot 24^{*}$ & $1.08,1.41$ & $1 \cdot 26^{\star}$ & $1.14,1.40$ \\
\hline Medium cities and suburbs & 1.07 & $0.92,1.24$ & $1 \cdot 30^{*}$ & $1.15,1.47$ & $1 \cdot 20^{*}$ & $1 \cdot 10,1.32$ \\
\hline Large cities & Ref. & & & & & \\
\hline \multicolumn{7}{|l|}{ Household size } \\
\hline 1 person & Ref. & & & & & \\
\hline 2 persons & 1.02 & $0.83,1.25$ & $1 \cdot 20^{*}$ & $1.01,1.42$ & $1 \cdot 10$ & $0.96,1.24$ \\
\hline 3 and more persons & $1 \cdot 19$ & $0.96,1.47$ & $1.53^{*}$ & $1.27,1.84$ & $1.35^{\star}$ & $1.18,1.55$ \\
\hline
\end{tabular}

Ref., reference.

* Significant difference indicated when $95 \% \mathrm{Cl}$ does not include the value '1'.

† OR from multiple logistic regressions with high meat consumption (Ref. low meat consumption) as the dependent variable and sociodemographic factors as independent variables.

affected these results. When taking the difference in energy intake into account, high meat consumers ate more potatoes and potato products, and sauces and spicy ingredients but less of most other food groups compared with low meat consumers. An additional adjustment for the sociodemographic differences had only minor effects on these results.

Table 6. Association between level of meat consumption and health-related characteristics, German National Nutrition Survey II $†$ (Odds ratios and $95 \%$ confidence intervals)

\begin{tabular}{|c|c|c|c|c|c|c|c|c|}
\hline & \multicolumn{2}{|c|}{$\begin{array}{l}\text { Normal weight } \\
\text { (Ref. preobese, } \\
\text { obese } \ddagger \text { ) }\end{array}$} & \multicolumn{2}{|c|}{$\begin{array}{l}\text { Non-smoking/former } \\
\text { smoking (Ref. smoking, } \\
\text { occasionally smoking) }\end{array}$} & \multicolumn{2}{|c|}{$\begin{array}{l}\text { Very good subjective } \\
\text { health (Ref. good, } \\
\text { moderate, poor, very } \\
\text { poor subjective health) }\end{array}$} & \multicolumn{2}{|c|}{$\begin{array}{l}\text { Sports activities§ } \\
\text { (Ref. 'no') }\end{array}$} \\
\hline & OR & $95 \% \mathrm{Cl}$ & OR & $95 \% \mathrm{Cl}$ & OR & $95 \% \mathrm{Cl}$ & OR & $95 \% \mathrm{Cl}$ \\
\hline \multicolumn{9}{|c|}{ Non-meat consumption (Ref. meat consumption), unadjusted } \\
\hline Men & $2.94^{\star}$ & $1.59,5.44$ & $1 \cdot 12$ & $0.57,2.17$ & $2 \cdot 79^{\star}$ & $1.51,5.18$ & 1.97 & $0.87,4.45$ \\
\hline Women & $4 \cdot 18^{\star}$ & $2 \cdot 70,6 \cdot 47$ & $1 \cdot 26$ & $0.83,1.93$ & $1 \cdot 81^{*}$ & $1.23,2.67$ & $1.98^{*}$ & $1.26,3 \cdot 10$ \\
\hline \multicolumn{9}{|c|}{ Non-meat consumption (Ref. meat consumption), adjusted } \\
\hline Men & 1.25 & $0.60,2.57$ & 1.43 & $0.67,3.04$ & 1.72 & $0.82,3.57$ & 1.26 & $0.53,3.01$ \\
\hline Women & $2 \cdot 55^{\star}$ & $1.57,4.14$ & 1.20 & $0.74,1.95$ & $1.58^{*}$ & $1.00,2.48$ & $1.82^{*}$ & $1.07,3 \cdot 10$ \\
\hline \multicolumn{9}{|c|}{ High meat consumption (Ref. low meat consumption), unadjusted } \\
\hline Men & $0.86^{\star}$ & $0.76,0.97$ & $0.75^{\star}$ & $0.66,0.86$ & 0.93 & $0.80,1.09$ & 0.92 & $0.79,1.06$ \\
\hline Women & $0.77^{\star}$ & $0.70,0.84$ & $0.76^{\star}$ & $0.68,0.85$ & 0.96 & $0.84,1.09$ & $0.68^{*}$ & $0.60,0.76$ \\
\hline \multicolumn{9}{|c|}{ High meat consumption (Ref. low meat consumption), adjusted } \\
\hline Men & 0.89 & $0.77,1.03$ & $0.82^{*}$ & $0.70,0.95$ & 0.96 & $0.91,1.14$ & 0.95 & $0.81,1 \cdot 11$ \\
\hline Women & $0.77^{\star}$ & $0.69,0.86$ & $0.78^{*}$ & $0.69,0.89$ & 1.05 & $0.91,1.21$ & $0.71^{*}$ & $0.62,0.80$ \\
\hline
\end{tabular}

Ref., reference.

* Significant difference indicated when $95 \% \mathrm{Cl}$ does not include the value '1'.

† OR from simple and multiple logistic regressions (adjusted for age, education, occupational position of the principal earner, per capita income, country of birth, regional structure, household size) with non-meat consumption or high meat consumption as the independent variables and health-related characteristics as dependent variables.

‡ Underweight subjects were excluded from the analysis.

$\S$ Information obtained from an additional questionnaire in a subsample. 
Table 7. Association between level of meat consumption and energy intake and energy density, German National Nutrition Survey II $\dagger$ (Regression coefficients $(B)$ and $95 \%$ confidence intervals)

\begin{tabular}{|c|c|c|c|c|c|c|}
\hline & \multicolumn{2}{|c|}{ Energy intake (kJ) } & \multicolumn{2}{|c|}{ Energy intake from meat $(\mathrm{kJ})$} & \multicolumn{2}{|c|}{ Energy density (kJ/g) } \\
\hline & $B$ & $95 \% \mathrm{Cl}$ & $B$ & $95 \% \mathrm{Cl}$ & $B$ & $95 \% \mathrm{Cl}$ \\
\hline \multicolumn{7}{|c|}{ Non-meat consumption (Ref. meat consumption), unadjusted } \\
\hline Men & 132 & $-836,1099$ & - & - & -0.63 & $-1.38,0.12$ \\
\hline Women & -73 & $-467,321$ & - & - & $-0.55^{\star}$ & $-0.90,-0.20$ \\
\hline \multicolumn{7}{|c|}{ Non-meat consumption (Ref. meat consumption), adjusted } \\
\hline Men & -360 & $-1405,685$ & - & - & $-0.86^{\star}$ & $-1.66,-0.06$ \\
\hline Women & -208 & $-656,239$ & - & - & $-0.64^{*}$ & $-1.04,-0.26$ \\
\hline \multicolumn{7}{|c|}{ High meat consumption (Ref. low meat consumption), unadjusted } \\
\hline Men & $1883^{*}$ & 1698,2068 & $1398^{*}$ & 1347,1448 & $0.74^{*}$ & $0.59,0.89$ \\
\hline Women & $1212^{*}$ & 1106,1319 & $911^{*}$ & 890,933 & $0.61^{*}$ & $0.51,0.70$ \\
\hline \multicolumn{7}{|c|}{ High meat consumption (Ref. low meat consumption), adjusted } \\
\hline Men & $1769^{*}$ & 1576,1963 & $1360^{*}$ & 1306,1414 & $0.66^{*}$ & $0.51,0.81$ \\
\hline Women & $1244^{*}$ & 1129,1359 & $915^{\star}$ & 891,938 & $0.60^{*}$ & $0.50,0.70$ \\
\hline
\end{tabular}

Ref., reference.

* Significant difference indicated when $95 \% \mathrm{Cl}$ does not include the value ' 0 '.

† Regression coefficients from simple and multiple linear regressions (adjusted for age, education, occupational position of the principal earner, per capita income, country of birth, regional structure, household size) with non-meat consumption or high meat consumption as the independent variable and energy intake or energy density as the dependent variables.

\section{Discussion}

This study described meat consumption and analysed the sociodemographic and health-related characteristics as well as the consumption behaviour of non-meat consumers, and low and high meat consumers in Germany. It revealed several key findings:

(1) In Germany, meat is consumed in large amounts: More than a half of the population consumed more meat than recommended.

(2) Gender aspects shape meat consumption behaviour: Among men, a lower proportion of non-meat consumers and a higher proportion of high meat consumers were observed compared with women.

(3) Age and education but also living environments also shape meat consumption behaviour: Non-meat consumption is more frequent among young and better-educated persons and among those living in single households, while high meat consumption is more frequent among young and middle-aged and lower-educated persons as well as among those living in small cities and rural areas and in larger households.

(4) Meat consumption behaviour is related to health-related lifestyles: While non-meat consumers showed equal or more preferable health characteristics compared with meat consumers, high meat consumers showed equal or less preferable health characteristics compared with low meat consumers.

(5) Non-meat consumers do not substitute meat with other animal-based foods: They had an equal energy intake but ate more plant-based foods and did not eat more fish/fish products/seafood, milk/dairy products/cheese or eggs compared with meat consumers.

(6) High meat consumers have high energy intakes and higher intakes of the traditional meal pattern components meat, potatoes and sauce: Their energy intake, especially their energy intake from meat, was higher compared with low meat consumers. When adjusting for energy intake, they ate more potatoes/potato products and sauces/spicy ingredients compared with low meat consumers and less of most other food groups.

\section{Meat consumption level}

In the past 20 years, different results regarding the prevalence of vegetarian diets in Germany have been published ranging from 2 to $10 \%{ }^{(21,22)}$, with data from the NVS II showing the lowest prevalence. In the NVS II, trained interviewers inquired about particular types of vegetarian diets (vegan, lacto-vegetarian, ovo-vegetarian, ovo-lacto-vegetarian or pesco-ovo-lacto-vegetarian) and provided the corresponding definitions when necessary. Additionally, the classification of a vegetarian diet was not enlarged by attributes like 'usually', 'largely' or 'predominantly'. This strict definition probably explains the low prevalence compared with other studies. Additionally, in the German National Nutrition Monitoring, a longitudinal study based on the NVS II, an increase in the prevalence of vegetarian diets was observed ${ }^{(23)}$. Therefore, changes over time might also explain part of the differences. Compared with previous NVS II results, the present analysis resulted in an even lower prevalence of non-meat consumers as additional consistency checks were performed with consumption data. Although the prevalences vary widely due to different assessment methods and definitions ${ }^{(21,22,24)}$ and vegetarian diets seem to gain popularity, the numbers indicate that only a minority of the German population follows a strict meat-free diet.

Instead, many Germans consume more meat than recommended and an adjustment of meat consumption to the dietary guidelines would require a behavioural change in more than half of the population. The literature on barriers and opportunities for meat reduction indicates that such a drastic change is unlikely to occur unless social-cultural transformation processes are initiated as well ${ }^{(25,26)}$. 


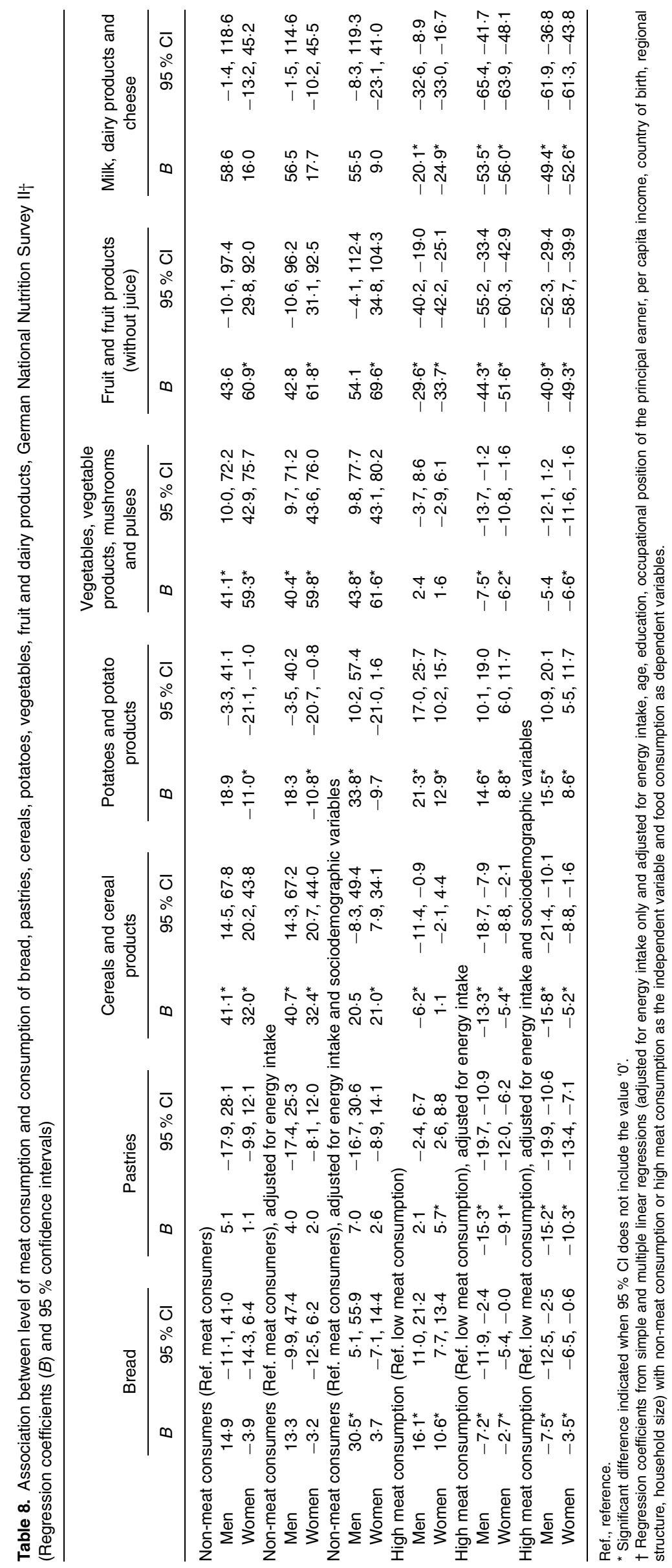




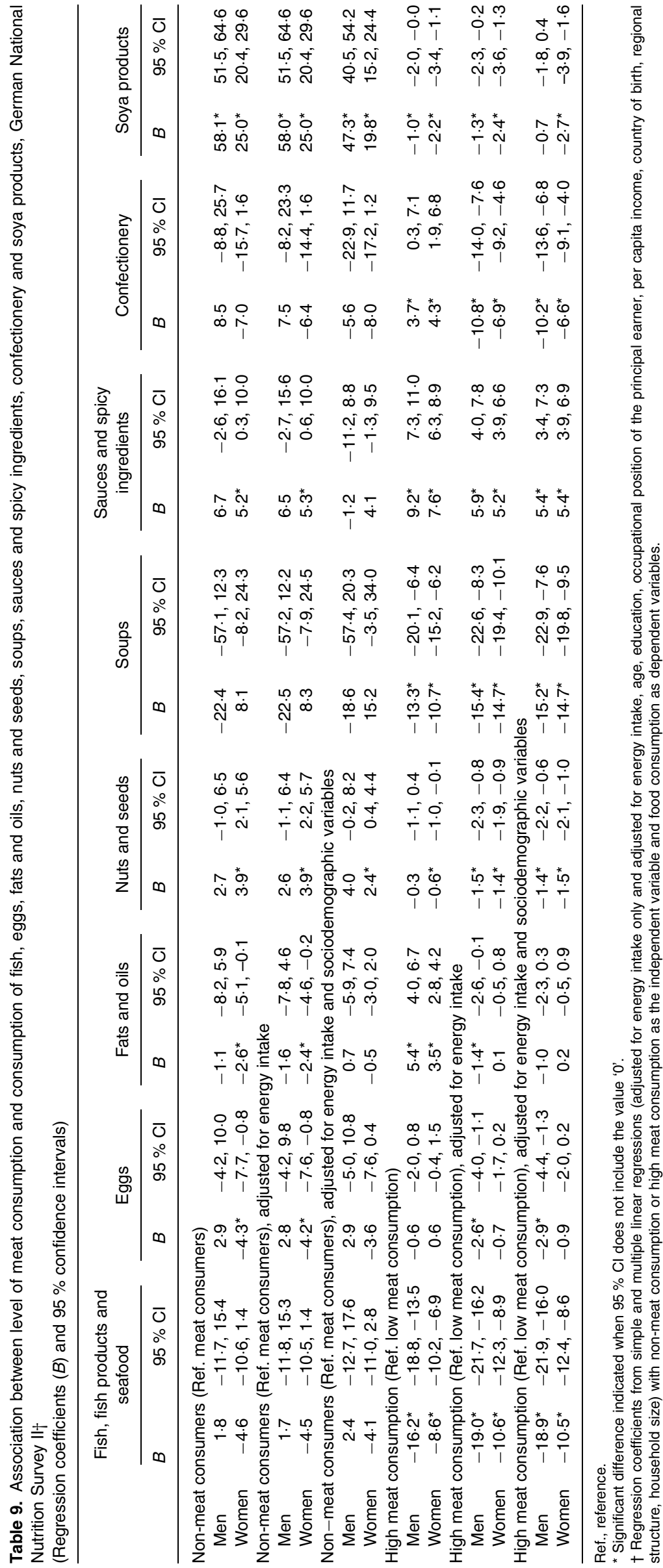




\section{Sociodemographic characteristics and meat consumption level}

The results confirm a large number of different studies linking female sex, younger age and better education to a non-meat/ vegetarian diet ${ }^{(21,22,27,28)}$. The higher proportion of female nonmeat consumers/vegetarians is usually explained by sociocultural aspects. According to the literature, meat is perceived as man's food with its symbolic associations with strength and power. Women, on the other hand, often show a lower preference for meat as they have stronger ethical concerns regarding animal welfare, are more interested in nutritional topics, and show a higher health and figure awareness ${ }^{(24,26,29)}$. For the higher proportion of non-meat consumers/vegetarians in younger and more-educated groups, different explanations could apply (e.g. higher interest in new nutritional topics, openness to trends, social positioning purposes (see below), higher environmental awareness). Previous literature also reports a higher proportion of vegetarians among urban residents ${ }^{(21,28)}$, probably for similar reasons. However, similar differences in the proportion of non-meat consumers could not be confirmed here. That a non-meat/vegetarian diet is more often observed among persons in single households - or as previously mentioned among persons living in smaller households ${ }^{(28)}$ and among singles ${ }^{(27)}$ - might indicate that following such a restrictive diet is easier without coordination and negotiation processes with other household members.

Higher consumption of meat and its subtypes, unadjusted and adjusted for energy intake, among men has been comprehensively reported in the literature ${ }^{(30,31)}$. Therefore, the higher meat consumption among men cannot be explained by men's generally higher energy requirements alone. Instead, as previously stated, different meat consumption patterns among sexes are usually explained by sociocultural aspects ${ }^{(24,26,29)}$. Traditional sex-specific role models and corresponding expectations still shape food consumption behaviour in general and meat consumption in particular. To this day meat consumption is shaped by traditional sex-specific role models and corresponding expectations. An inverse relationship between education and meat consumption has also been frequently reported $^{(30-32)}$. This might be due to greater health orientation and a higher awareness of the adverse effects of meat consumption among better-educated individuals. Limited consumption of meat might also function as a means of social distinction. Today, meat is obtainable (almost) everywhere at relatively low prices and it seems to have lost its attribute as a status symbol. Therefore, reducing meat consumption or entirely abstaining from meat may appear morally superior due to the adverse ethical, ecological and health effects of (high) meat consumption ${ }^{(29)}$. According to SchlegelMatthies ${ }^{(29)}$, such processes of social positioning might also explain differences in meat consumption between urban and rural residents, as observed here. Besides, lower meat consumption among urban residents might be explained by their openness towards new trends as well as a higher availability and variety of vegetarian options in cities.

Gossard \& York ${ }^{(32)}$ and Linseisen et al. ${ }^{(31)}$ report that the amount of consumed meat decreases with increasing age. In this sample, a similar trend could be observed, and it seems reasonable that older persons consume less meat as a result of lower energy needs and higher health awareness. However, our results showed that a linear model is not optimally suited to describe the relationship between age and proportion of high meat consumers. Therefore, the association between age and meat consumption might warrant further investigation. This might also apply to household size. Our results suggest that females might adopt higher meat consumption of other household members, but meat consumption was seldom analysed according to household size or family status before, which makes this a hypothetical assumption.

To conclude, sociodemographic groups show differences in their meat consumption level and there is good evidence that initiatives and campaigns aiming to reduce meat consumption to the recommended level should primarily address men as well as young and middle-aged and persons with lower education. However, it must be noted that differences except for sex are not very large and that sociodemographic characteristics only explain a small part of the variation in meat consumption level. Differences in meat consumption might rather be explained by different attitudes. Another analysis (in preparation) should provide further information in this regard.

\section{Meat consumption level and health-related characteristics}

More preferable health characteristics - in terms of BMI, sports activities and smoking status - among vegetarians compared with meat consumers were previously reported ${ }^{(21,27,33)}$ The results suggest that a non-meat/vegetarian diet can be considered as part of an overall health-conscious lifestyle. This is not surprising since personal health is one of the main motivations to adopt a vegetarian $\operatorname{diet}^{(24)}$.

Also consistent with our findings, associations between higher meat consumption and less favourable health-related characteristics were previously described ${ }^{(30,31)}$. Therefore, high meat consumption might be embedded in an overall less healthy lifestyle. This suggests that the reduction of high meat consumption to a healthy and sustainable level should be addressed as one of several health behaviours in complex health promotion programmes ${ }^{(34)}$.

\section{Meat consumption level and energy intake and food consumption}

Our results indicate that non-meat consumers do not substitute meat with fish, eggs or milk products but rather with soya products and other foods of plant origin. Relatively large amounts of cereals, vegetables, fruit, nuts and pulses are described as common for a vegetarian diet ${ }^{(33)}$. However, previous results reveal no clear answer to the question whether meat is substituted with other animal products in vegetarian diets. For example, Bedford \& Barr $^{(27)}$ found a higher consumption of milk products among male vegetarians while Mensink et al. ${ }^{(21)}$ observed a higher consumption of milk products but a lower consumption of eggs among female vegetarians compared with meat consumers. In contrast, Haddad \& Tanzman ${ }^{(35)}$ found no differences in milk product consumption between 
vegetarians and non-vegetarians. Nonetheless, the results presented here comply with findings that non-meat consumers/ vegetarians to a larger extent adhere to dietary recommendations $^{(35)}$, which reflects their more health-conscious lifestyle.

Similar to our results, associations between higher levels of meat consumption and higher energy intake have been reported previously ${ }^{(31,36)}$. The results further indicate that high meat consumers might more strongly adhere to the classical meal structure of meat (as the centrepiece) with potatoes and gravy. Their diet seems to be less varied compared with those of participants with lower meat consumption. According to de Boer et al. ${ }^{(37)}$ there are different, complementary change strategies to reduce meat consumption in current high-meat-eating societies: Promoting smaller portions of meat in a meal, either in favour of meat raised in a more sustainable manner ('less but better') or in favour of more vegetable protein ('less and more varied'), or promoting meatless days ('veggie days'). Our results suggest that it might be easier for current high meat consumers to reduce meat portions in the preferred traditional meal structure than to adopt new vegetarian meals. In any case, meat-reduced or vegetarian meals need to be highly appealing, easy to prepare and simple to adopt into current habits to be accepted as a genuine alternative.

\section{Strengths and limitations}

This is the first study using the nationally representative data of the NVS II to compare non-meat consumers and meat consumers as well as low meat consumers (meeting the dietary recommendation of the German Nutrition Society to eat no more than 300 to $600 \mathrm{~g}$ meat per week) and high meat consumers (eating more meat than recommended). It adds further evidence to previous studies showing that non-meat/vegetarian and low-meat diets are more frequent among women and better-educated persons and that following such a diet seems to fit into an overall healthier lifestyle.

However, the present study has several limitations. It was based on data collected about 10 years ago. In this time span, many trend messages about vegetarian and vegan lifestyles were disseminated and those diets and lifestyles received high media attention. Thus, it is possible that changes have occurred in the prevalence of non-meat diets as well as the factors associated with them. It is also important to note that we analysed non-meat consumers who may include fish in their diet instead of vegetarians. This could have affected the results, which might have been clearer if the focus had been on persons who abstain from eating meat and fish. Moreover, despite the large overall sample size, the number of non-meat consumers was very low, especially for sexspecific analyses. Given the high scientific interest in non-meat consumers, this paper aimed to use the given data to provide detailed and complete information on this group. However, analyses based on this small number warrant serious caution and should be understood as exploratory. Since the data came from a cross-sectional survey, only associations can be reported and interpretations about causality are not permitted.

With regard to the amount of meat consumed, the large time span since data collection is assumed to have no substantial effect on the results. The German National Nutrition Monitoring showed that meat consumption was stable between 2006 and 2014, even among subgroups of the population ${ }^{(38)}$. The maximum amount of meat consumption recommended by the German Nutrition Society was used as a single cut-off point to divide the meat consumers sample into low and high meat consumers, based on their consumption behaviour on two recall days. This approach might produce misleading results for those individuals whose meat consumption was close to the recommended amount. However, analyses were also performed with the amount of meat consumed as a continuous variable. Since results were largely comparable, the classification according to the reference values was presented for better interpretability.

Despite these limitations, this study can add further valuable insights on (non-)meat consumption in Germany.

\section{Conclusion}

Meat consumption in Germany is above the recommended level. In particular, sex differences shape meat consumption behaviour: men are less likely to abstain from meat and more likely to consume meat in exaggerated amounts. Meat consumption behaviour is further influenced by age, education, household size and rural/urban living environments. Health behaviours and food consumption patterns differ by meat consumption behaviour. Explanations for the findings and implications for a reduction of meat consumption were discussed.

This paper provides further insights to the issue of nonmeat consumption and high meat consumption. However, future research also needs to consider attitudes towards meat and social-cultural aspects of meat consumption to gain a better understanding of meat consumption behaviour and ways to reduce it to the recommended level.

\section{Acknowledgements}

The NVS II was funded by the German Federal Ministry of Food, Agriculture and Consumer Protection. The Ministry had no role in the design, analysis or writing of this article.

F. K. analysed and interpreted the data and drafted the manuscript. C. K. and T. H. were involved in study design and data interpretation and critically reviewed the manuscript. E. C. initiated and designed the research, contributed to data interpretation and manuscript preparation, critically reviewed the manuscript and had primary responsibility for the final content. All authors read and approved the final version of the manuscript.

There were no conflicts of interest.

\section{References}

1. Westhoek H, Rood T, von den Berg M, et al. (2011) The Protein Purzle: The Consumption and Production of Meat, Dairy and Fish in the European Union. The Hague: PBL Netherlands Environmental Assessment Agency.

2. Westhoek H, Lesschen JP, Rood T, et al. (2014) Food choices, health and environment: effects of cutting Europe's meat and dairy intake. Glob Environ Change 26, 196-205. 
3. Ranganathan J, Vennard D, Waite R, et al. (2016) Shifting Diets for a Sustainable Food Future. Washington, DC: World Resources Institute.

4. Loughnan S, Haslam N \& Bastian B (2010) The role of meat consumption in the denial of moral status and mind to meat animals. Appetite 55, 156-159.

5. Piazza J, Ruby MB, Loughnan S, et al. (2015) Rationalizing meat consumption. The 4Ns. Appetite 91, 114-128.

6. World Cancer Research Fund \& American Institute for Cancer Research (2007) Food, Nutrition, Physical Activity, and the Prevention of Cancer: A Global Perspective. Washington, DC: AICR.

7. Fardet A \& Boirie Y (2014) Associations between food and beverage groups and major diet-related chronic diseases: an exhaustive review of pooled/meta-analyses and systematic reviews. Nutr Rev 72, 741-762.

8. Horrigan L, Lawrence RS \& Walker P (2002) How sustainable agriculture can address the environmental and human health harms of industrial agriculture. Environ Health Perspect 110, 445-456.

9. McMichael AJ, Campbell-Lendrum DH, Corvalán CF, et al. (2003) Climate Change and Human Health: Risks and Responses. Geneva: World Health Organization.

10. McMichael AJ, Powles JW, Butler CD, et al. (2007) Food, livestock production, energy, climate change, and health. Lancet 370, 1253-1263.

11. Goodland R \& Anhang J (2009) Livestock and Climate Change: What if the Key Actors in Climate Change are... Cows, Pigs, and Chickens? Washington, DC: Worldwatch Institute.

12. Steinfeld H, Gerber P, Wassenaar T, et al. (2006) Livestock's Long Shadow: Environmental Issues and Options, Livestock's Long Shadow: Environmental Issues and Options. Rome: Food and Agriculture Organization of the United Nations.

13. Tobler C, Visschers VHM \& Siegrist M (2011) Eating green. Consumers' willingness to adopt ecological food consumption behaviors. Appetite 57, 674-682.

14. DGE (2014) Lebensmittelberogene Ernäbrungsempfeblungen in Deutscbland (Food Based Recommendations in Germany). Bonn: Deutsche Gesellschaft für Ernährung.

15. Heuer T, Krems C, Moon K, et al. (2015) Food consumption of adults in Germany: results of the German National Nutrition Survey II based on diet history interviews. Br J Nutr 113, 1603-1614.

16. MRI (2008) Nationale Verzehrsstudie II. Ergänzungsband zum Ergebnisbericht, Teil 1 (National Nutrition Survey II. Supplement to First Report). Karlsruhe: Max Rubner-Institut.

17. Slimani N, Deharveng G, Charrondière RU, et al. (1999) Structure of the standardized computerized 24-h diet recall interview used as reference method in the 22 centers participating in the EPIC project. Comput Meth Programs Biomed 58, 251-266.

18. Hartmann BM, Heuer T \& Hoffmann I (2015) The German Nutrient Database: effect of different versions on the calculated energy and nutrient intake of the German population. J Food Compos Anal 42, 26-29.

19. BIK Aschpurwis+Behrens (2001) BIK-Regionen. Ballungsräume, Stadtregionen, Mittel-/Unterzentrengebiete. Methodenbeschreibung zur Aktualisierung 2000 (BIK Regions. Metropolitan Areas, City Regions, Central/Sub-Central Areas. Method Description for Updating 2000). Hamburg: BIK Aschpurwis+Behrens GmbH.

20. World Health Organization (2000) Obesity: Preventing and Managing the Global Epidemic. Report of a WHO Consultation. Technical Report Series no. 894. Geneva: WHO.
21. Mensink GBM, Lage Barbosa C \& Brettschneider A-K (2016) Prevalence of persons following a vegetarian diet in Germany. $J$ Health Monit 1, 2-14.

22. Pfeiler TM \& Egloff B (2018) Examining the 'Veggie' personality: results from a representative German sample. Appetite 120, 246-255.

23. MRI (2018) Längsschnittstudie NEMONIT (NEMONIT longitudinal study). https://www.mri.bund.de/de/institute/ernaehrungs verhalten/forschungsprojekte/nemonit/ (accessed May 2018).

24. Ruby MB (2012) Vegetarianism. A blossoming field of study. Appetite 58, 141-150.

25. Clausen J \& Mathes M (2017) Fleischkonsum. Transformationsfeldanalyse im Rahmen des Projekts Evolution2Green (Meat Consumption. Transformation Field Analysis Witbin the Project Evolution2Green). Berlin: Adelphi Research, Borderstep Institut für Innovation und Nachhaltigkeit, ZT-Institut für Zukunftsstudien und Technologiebewertung.

26. Stoll-Kleemann S \& Schmidt J (2017) Reducing meat consumption in developed and transition countries to counter climate change and biodiversity loss: a review of influence factors. Reg Environ Change 17, 1261-1277.

27. Bedford JL \& Barr SI (2005) Diets and selected lifestyle practices of self-defined adult vegetarians from a population-based sample suggest they are more 'health conscious'. Int J Behav Nutr Phys Act $2,4$.

28. Hoek AC, Luning PA, Stafleu A, et al. (2004) Food-related lifestyle and health attitudes of Dutch vegetarians, non-vegetarian consumers of meat substitutes, and meat consumers. Appetite 42, 265-272.

29. Schlegel-Matthies K (2015) Fleisch in unserer Gesellschaft (Meat in our society). Ernährung im Fokus 15, 256-261.

30. Aston LM, Smith JN \& Powles JW (2013) Meat intake in Britain in relation to other dietary components and to demographic and risk factor variables: analyses based on the National Diet and Nutrition Survey of 2000/2001. J Hum Nutr Diet 26, 96-106.

31. Linseisen J, Kesse E, Slimani N, et al. (2002) Meat consumption in the European Prospective Investigation into Cancer and Nutrition (EPIC) cohorts: results from 24-hour dietary recalls. Public Health Nutr 5, 1243-1258.

32. Gossard MH \& York R (2003) Social structural influences on meat consumption. Human Ecology Review 10, 1-9.

33. Key TJ, Appleby PN \& Rosell MS (2006) Health effects of vegetarian and vegan diets. Proc Nutr Soc 65, 35-41.

34. Gregório MJ, Rodrigues AM, Eusébio M, et al. (2017) Dietary patterns characterized by high meat consumption are associated with other unhealthy life styles and depression symptoms. Front Nutr $4,25$.

35. Haddad EH \& Tanzman JS (2003) What do vegetarians in the United States eat? Am J Clin Nutr 78, Suppl. 3, 626-632.

36. de Carvalho AM, César CLG, Fisberg RM, et al. (2013) Excessive meat consumption in Brazil: diet quality and environmental impacts. Public Health Nutr 16, 1893-1899.

37. de Boer J, Schosler H \& Aiking H (2014) "Meatless days" or "less but better"? Exploring strategies to adapt Western meat consumption to health and sustainability challenges. Appetite 76, 120-128.

38. Römer K, Koch F, Claupein E, et al. (2017) High meat consumption is stable between 2006 and 2014 in the NEMONIT study. Poster. Max Rubner Conference 2017 - Nutrition Monitoring Challenges and Developments. 